\title{
Monitoring of the HIV-Positive Mother-Child Couple at the Provincial General Reference Hospital of Kinshasa
}

\author{
Thessy Tshibi Bindanda1, Divine Chuga ${ }^{1,2}$, Jean Yves Debels Kabasele², Ben Ilunga Bulanda, \\ Berry Ikolango Bongenya ${ }^{1,2}$, Erick Ntambwe Kamangu ${ }^{2,3 *}$ \\ ${ }^{1}$ Faculty of Medicine, Technological University Bel Campus, Kinshasa, Democratic Republic of Congo \\ 2“Focus HIV/AIDS” Research Group, Kinshasa, Democratic Republic of Congo \\ ${ }^{3}$ Service of Molecular Biology, Department of Basic Sciences, Faculty of Medicine, University of Kinshasa, Kinshasa, Democratic \\ Republic of Congo \\ Email: *erick.kamangu@unikin.ac.cd
}

How to cite this paper: Bindanda, T.T., Chuga, D., Kabasele, J.Y.D., Bulanda, B.I., Bongenya, B.I. and Kamangu, E.N. (2021) Monitoring of the HIV-Positive Mother-Child Couple at the Provincial General Reference Hospital of Kinshasa. Open Access Library Journal, 8: e7274.

https://doi.org/10.4236/oalib.1107274

Received: March 1, 2021

Accepted: August 14, 2021

Published: August 17, 2021

Copyright $\odot 2021$ by author(s) and Open Access Library Inc.

This work is licensed under the Creative Commons Attribution International License (CC BY 4.0).

http://creativecommons.org/licenses/by/4.0/

\begin{abstract}
Context: Vertical transmission of HIV is the main route of pediatric contamination in Sub-Saharan Africa, which despite everything remains insufficiently covered. Objective: The objective of this study was to assess the care of the HIV-positive mother-child couple at the Provincial General Reference Hospital in Kinshasa according to the general recommendations of Prevention of Mother-to-Child Transmission Program (PMCT). Methods: The present work is a retrospective study carried out mainly on the files of HIV-positive mother-child couples followed at the Kinshasa General Referral Hospital PMCT service, whose mothers were $\geq 18$ years old and diagnosed positive for HIV using at least 2 screening tests during the period from February 2015 to March 2019. Results: Out of 206 files found in the PMCT service at the Hospital, 61 files (29.6\%) were retained based on the completeness of the data in these files. The most represented age group is 23 to 27 years with 21 mothers (34.4\%). Most mothers were married (59.0\%). The majority of mothers tested positive for HIV were on WHO Stage 1 (72.1\%). Most started Prenatal Consultation in the $3^{\text {rd }}$ trimester of pregnancy $(60.7 \%)$. The most common ARV treatment is the TDF + 3TC + EFV combination in $75.4 \%$ of mothers. The most common delivery method was the low route at 83.6\%. More than half of the pregnancies carried gave birth to girls (55.7\%). The most represented birth weight group was that of less than $2500 \mathrm{~g}$ with 27 children (39.2\%). The most common ARV prophylaxis in children was Nevirapine in monotherapy (81.9\%). Cotrimoxazole was supplemented in $81.9 \%$ of the children. After PCR diagnosis, 5 children (8.2\%) were positive for HIV. Breastfeeding was the most common feeding method at $85.3 \%$. Conclusion:
\end{abstract}


Although the care of the mother-child couple is correct, the transmission rate still remains high at $8.2 \%$ at the Provincial General Reference Hospital of Kinshasa for the period evaluated.

\section{Subject Areas}

HIV

\section{Keywords}

HIV, Mother-to-Child Transmission, PMCT, PGRHK, Kinshasa

\section{Introduction}

Acquired Immunodeficiency Syndrome known as AIDS is a disease that causes a drop in the natural immune system caused by the Human Immunodeficiency Virus (HIV) [1]. It is a global public health problem, which resulted in more than 32 million deaths and an estimated 37.9 million people were infected with HIV by the end of 2018 [1]. According to the joint program's global report United Nations Conference on HIV/AIDS (UNAIDS) was made public on Thursday, November 22, 2018 in Abidjan, Côte d'Ivoire. The number of people living with HIV increased from 36.3 million in 2016 to 36.9 million in 2017, including 35.1 million adults and 1.8 million children under the age of 15 , while the number of deaths was reduced from 990,000 to 940,000 [2].

Vertical transmission (mother-to-child) of HIV is the main route of infection in Sub-Saharan Africa [3]. This transmission can take place during pregnancy, labor, delivery or breastfeeding. Transmission rates vary from $15 \%$ to $45 \%$ in the absence of intervention, but can be significantly reduced to less than $5 \%$ if adequate measures are implemented [4].

In 2018 in the Democratic Republic of Congo (DRC), there were around 450,000 People Living with HIV (PLHIV), 19,000 new infections and 17,000 people died from AIDS-related illnesses. In addition, there is an over-representation of women among infected people in the DRC $(71.79 \%)$ of infected people. New infections among young women aged $15-24$ are more than four times that of young men [5]. The DRC is one of the countries in Sub-Saharan Africa with a high rate of mother-to-child transmission and unsatisfied needs in the Prevention of Mother-to-Child Transmission Program (PMCT) [6] which, launched at the beginning of 2001 mainly in Kinshasa and gradually extended to other provinces. The PMCT program intensified in 2012 thanks to support from international partners. According to WHO's recommendations, pregnant women, in general, should start PreNatal Consultation (PNC) from the first trimester; and HIV positive mother should respect them at the most [4]. Therefore the PMCT program emphasizes the respect of the PNC appointment, AntiRetroViral Treatment (ART), delivery and child-feeding option [4]. 
In spite of all this, the country remains insufficiently covered by AIDS services and even where services exist, the offer of the prevention, care and treatment package in health structures is incomplete. The use of PMCT services is still very low in the DRC.

Thus the objective of this study was to assess the care of the HIV-positive mother-child couple at the Provincial General Reference Hospital in Kinshasa according to the general recommendations of Prevention of Mother-to-Child Transmission Program (PMCT).

\section{Methods}

The present work is a study carried out at the Provincial General Reference Hospital of Kinshasa (PGRHK). This is a retrospective study carried out mainly on the files of seropositive mother-child couples monitored at the PGRHK in the Prevention of Mother-to-Child Transmission (PMCT) service during the period from February 2015 to March 2019.

Patients were included in the present study based on a modeled survey form and on very specific criteria: 1 ) records of pregnant women of at least 18 years, diagnosed HIV-positive confirmed by at least 2 Rapid Diagnostic Tests (RDT-Determines, Unigold, and/or Double Check); with confirmation with a $3^{\text {rd }} \mathrm{RDT}$ in case of doubt according to WHO recommendation [4]; 2) women were followed in the PNC program and had given birth in the PMCT service in the center; 3) records containing all anthropometric and socio-demographic data. The important information had been collected from the records of the mother-child couple on different parameters of interest. For the mothers: 1) their age, 2) the age of pregnancy at the beginning of prenatal consultation, 3) the date of HIV testing, 4) the method of diagnosis, 5) the clinical stage at start, 6) the type of treatment regimen and 7) the treatment start date were selected as parameters of interest. For the newborns: 1) date of birth, 2) gender, 3) weight, 4) height, 5) therapeutic regimen at birth, 6) date of screening, and 7) the diagnostic method were used as the parameter of interest. All data were transcribed in a pre-tested spreadsheet. All the records that did not have all the information listed (missing data, unclear results, ...) were not included in the study.

All information collected concerning the women and children who participated was kept confidential. This study had received the consent of the institution.

\section{Results}

During the period of our study, 206 files of the HIV-positive mother and child couple were found in the PMCT service at the Hospital, 61 files (29.6\%) were retained based on the completeness of the data in these files.

The most represented age group is that of 23 to 27 years with 21 mothers (34.4\%), followed by that of 18 to 22 years (26.2\%), that of 33 to 37 years $(19.7 \%)$ and those aged 28 to 32 (14.8\%). Most mothers were married (59.0\%) followed by single (37.7\%) and divorced (3.3\%). The majority of mothers tested positive 
for WHO Stage 1 HIV (72.1\%). Most started Prenatal Consultation (PNC) in the $3^{\text {rd }}$ trimester of pregnancy $(60.7 \%)$. The most common ARV treatment is the Tenofovir (TDF), Lamivudine (3TC) and Efavirenz (EFV) combination in $75.4 \%$ of mothers. The most common delivery method was the low route at $83.6 \%$. Table 1 shows the data presented above.

More than half of the pregnancies carried gave birth to girls (55.7\%). The most represented birth weight group was that of less than $2500 \mathrm{~g}$ with 27 children (39.2\%) followed by that of $2500 \mathrm{~g}$ to $3000 \mathrm{~g}$ (29.4\%). The most common ARV prophylaxis in children was Nevirapine in monotherapy (81.9\%). Cotrimoxazole was supplemented in $81.9 \%$ of the children. After Polymerase Chain reaction (PCR) diagnosis, 5 children (8.2\%) were positive for HIV. Breastfeeding was the most common feeding method at $85.3 \%$. Table 2 presents the data of the children presented here.

Only relevant information on the mother-child couple for the study have been presented in this publication.

Table 1. Parameters of mothers followed in the center.

\begin{tabular}{|c|c|c|}
\hline \multirow{2}{*}{ Parameters } & \multicolumn{2}{|c|}{ Frequencies } \\
\hline & $\mathbf{n}$ & $\%$ \\
\hline \multicolumn{3}{|l|}{ Age interval } \\
\hline $18-22$ & 16 & 26.2 \\
\hline $23-27$ & 21 & 34.4 \\
\hline $28-32$ & 9 & 14.8 \\
\hline $33-37$ & 12 & 19.7 \\
\hline $38-42$ & 2 & 3.3 \\
\hline+42 & 1 & 1.6 \\
\hline \multicolumn{3}{|l|}{ Civil Status } \\
\hline Single & 23 & 37.7 \\
\hline Married & 36 & 59.0 \\
\hline Divorced & 2 & 3.3 \\
\hline \multicolumn{3}{|c|}{ Clinical Stage according to WHO } \\
\hline Stage 1 & 44 & 72.1 \\
\hline Stage 2 & 17 & 27.9 \\
\hline Stage 3 & 0 & 0 \\
\hline Stage 4 & 0 & 0 \\
\hline \multicolumn{3}{|c|}{ Start of prenatal consultation } \\
\hline $1^{\text {rst }}$ trimester & 6 & 9.8 \\
\hline $2^{\text {nd }}$ trimester & 18 & 29.5 \\
\hline $3^{\text {rd }}$ trimester & 37 & 60.7 \\
\hline \multicolumn{3}{|l|}{ Therapeutic combination } \\
\hline $\mathrm{TDF}+3 \mathrm{TC}+\mathrm{EFV}$ & 46 & 75.4 \\
\hline $\mathrm{AZT}+3 \mathrm{TC}+\mathrm{EFV}$ & 15 & 24.6 \\
\hline \multicolumn{3}{|l|}{ Mean of birth } \\
\hline Low route & 51 & 83.6 \\
\hline C-section & 10 & 16.4 \\
\hline
\end{tabular}


Table 2. Parameters of children born from HIV-positive mothers followed in the center.

\begin{tabular}{|c|c|c|}
\hline \multirow{2}{*}{ Parameters } & \multicolumn{2}{|c|}{ Frequencies } \\
\hline & $\mathbf{n}$ & $\%$ \\
\hline \multicolumn{3}{|l|}{ Sex of children born } \\
\hline Girls & 34 & 55.7 \\
\hline Boys & 27 & 44.3 \\
\hline \multicolumn{3}{|c|}{ Weight of children at birth (in grams) } \\
\hline$<2500$ & 27 & 39.2 \\
\hline $2500-3000$ & 18 & 29.4 \\
\hline $3000-3500$ & 8 & 15.7 \\
\hline $3500-4000$ & 5 & 9.8 \\
\hline$>4000$ & 3 & 5.9 \\
\hline \multicolumn{3}{|l|}{ ARV Prophylaxis at birth } \\
\hline NVP & 50 & 81.9 \\
\hline $\mathrm{AZT}+3 \mathrm{TC}+\mathrm{NVP}$ & 11 & 18.1 \\
\hline \multicolumn{3}{|c|}{ Prophylaxis with Cotrimoxazole } \\
\hline YES & 50 & 81.9 \\
\hline NO & 11 & 18.1 \\
\hline \multicolumn{3}{|l|}{ Results HIV diagnostic } \\
\hline VIH positive & 5 & 8.2 \\
\hline VIH negative & 56 & 91.8 \\
\hline \multicolumn{3}{|l|}{ Mean of feeding } \\
\hline Maternal milk & 52 & 85.3 \\
\hline Artificial milk & 8 & 13.1 \\
\hline Combination of both & 1 & 1.6 \\
\hline
\end{tabular}

\section{Discussion}

The objective of this study was to describe and evaluate the care of the HIV-positive mother-child couple at the Provincial General Reference Hospital of Kinshasa (PGRHK) according to the general recommendations of the Prevention of Mother-to-Child Transmission (PMCT).

The most represented age group is that of 23 to 27 years with 21 mothers (34.4\%), followed by that of 18 to 22 years (26.2\%), that of 33 to 37 years (19.7\%) and those aged 28 to 32 (14.8\%). Chuga et al., in 2018, found the 26 to 35 years age group to be the most represented in the population of PLHIV women in Kinshasa [7]. This difference may simply be due to the difference in health infrastructures and the populations that frequent them.

Most mothers were married (59.0\%) followed by single (37.7\%) and divorced (3.3\%). Kimbala et al., in Lubumbashi in 2016, had described a large number of married women during consultations with PLHIV [8]. These data confirm the place of marriage in African society where it is still not conceived for a woman to raise a child outside of marriage.

The majority of mothers tested positive for WHO Stage 1 of HIV (72.1\%). These data are confirmed by Chuga et al. who found $73.2 \%$ of women screened 
in WHO Stage 1 [7]. This early screening promotes the management of pregnant women and also reduces the rate of vertical transmission.

Most started Prenatal Consultation (PNC) in the $3^{\text {rd }}$ trimester of pregnancy (60.7\%). These results demonstrate the non-compliance with the recommendations for monitoring pregnancies in this structure. Nevertheless, in their study of the 4 districts of the city, Chuga et al. presented $46.3 \%$ of mothers who started PNC in the $2^{\text {nd }}$ trimester [7]. This shows that, on the whole, the standards for monitoring pregnancies are more or less respected in the city of Kinshasa.

The most common ARV treatment is the TDF + 3TC + EFV combination in $75.4 \%$ of mothers. These results demonstrate compliance with the national policy for the care of PLWHIV published by the National Program for the Fight against HIV/AIDS and Sexually Transmitted Infections which recommends the combination TDF $+3 \mathrm{TC}+\mathrm{NVP}$ or EFV as preferential treatment for pregnant women [9].

The most common delivery method was the low route at $83.6 \%$. These results are opposed to the recommendations for the management of pregnant women, which call for giving priority to deliveries by upper route for HIV-positive mothers to avoid possible contamination of the child during childbirth [9]. However, this method of delivery is also found to be $91.7 \%$ dominant in the work of Kimbala et al. in Lubumbashi [8].

More than half of the pregnancies carried gave rise to girls (55.7\%). The most represented birth weight group was that of less than $2500 \mathrm{~g}$ with 27 children (39.2\%) followed by that of $2500 \mathrm{~g}$ to $3000 \mathrm{~g}$ (29.4\%). The low birth weight of children born to HIV-positive mothers has been described in several studies [10].

The most common ARV prophylaxis in children was Nevirapine in monotherapy (81.9\%). Cotrimoxazole was supplemented in $81.9 \%$ of children.

After PCR diagnosis, 5 children (8.2\%) were positive for HIV. This prevalence is slightly higher than that of $2 \%$ presented by Chuga et al. in 2018 [7]. This difference may be due to the different populations studied, to the standards for monitoring mother-child pairs in the different centers, but also to the socio-economic aspects of the mothers monitored in the different centers.

Breastfeeding was the most common feeding method at $85.3 \%$. These results are contrary to that of Lubumbashi where $94.12 \%$ of children born to HIV-positive mothers were placed on artificial breastfeeding systems [8]. This shows how the recommendations on breastfeeding children born to HIV-positive mothers are not respected in all centers in the country.

\section{Limitation of the Study}

This study is a retrospective one conducted in one PMCT service in one center. Therefore, only available data have been recorded to be presented. The type and the restriction of the study did not allow to have more information on the patients such as clinical characteristics of mothers before and after the treatment. 


\section{Conclusion}

One of the main modes of acquisition of pediatric HIV is still mother-to-child transmission of HIV/AIDS. Although the care of the mother-child couple is correctly done, the transmission rate still remains high, 8.2\%, at the Provincial General Reference Hospital of Kinshasa for the period evaluated. Hence, adequate measures should be implemented for HIV-positive pregnant women.

\section{Authors' Contribution}

TTB and ENK: conception and design, analysis and interpretation, drafting the article. DC, JYDK, BII1 and BII2: conception and design, critical revision of the article, final approval of the article. TTB: collection data. ENK: critical revision of the final version of the article, final approval of the article. All the authors have read and agreed to the final manuscript.

\section{Conflicts of Interest}

The authors declare no conflicts of interest.

\section{References}

[1] Organisation Mondiale de la Santé (OMS) (2020) VIH/SIDA dans le monde. https://www.who.int/

[2] Organisation des Nations Unies pour le VIH/SIDA (ONUSIDA) (2017) Plan de rattrapage de l'Afrique de l'Ouest et du Centre. Accélérer le traitement du VIH d'ici à 2018. ONUSIDA.

[3] Little, K.E., Bland, R.M. and Newell, M.L. (2008) Vertically Acquired Paediatric HIV Infection: The Challenges of Providing Comprehensive Packages of Care in Resource-Limited Settings. Tropical Medicine \& International Health, 13, 1098-1110. https://doi.org/10.1111/j.1365-3156.2008.02130.x

[4] Organisation Mondiale de la Santé (OMS) (2017) VIH/SIDA: Transmission du VIH de la mère à l'enfant.

[5] Organisation des Nations Unies pour le VIH/SIDA (ONUSIDA) (2019) Rapport Mondial sur l'épidémie du SIDA.

[6] Organisation des Nations Unies pour le VIH/SIDA (ONUSIDA) (2017) Le VIH/sida en chiffres /République démocratique du Congo.

[7] Chuga, D., Bulanda, B.I., Kabasele, D., Kabasele, J.Y.D., Okonda, M.O., Bongenya, B.I. and Kamangu, E.N. (2018) Vertical Transmission Rate of HIV from Seropositive Mothers Followed in the Different Care Centers in Kinshasa from 2010 to 2015. Open Access Library Journal, 5, e4769. https://doi.org/10.4236/oalib.1104769

[8] Kimbala, J., Mukuku, O., Tshimanga, K.C., Kapend, L., Numbi, L.O., Nsambi, J., Muteba, F., Mande, J., Ngoy, K.F., Lufwa, D.I., Matembo, P. and Kizonde, J. (2016) Transmission du VIH de la mère à l'enfant à Lubumbashi (République Démocratique du Congo): Leçons à tirer des résultats auprès de 6 maternites de référence de 2007 à 2012. Médecine d'Afrique Noire, 63, 161-173.

[9] Programme National de Lutte contre le VIH/SIDA et les Infecttions Sexuellement Transmissibles (PNLS), Ministère de la Santé Publique, République Démocratique du Congo (2016) Guide de prise en charge intégrée du VIH en RDC.

[10] Berebi, A. (2001) Le SIDA au féminin. Edition DOIN, Paris, 205. 


\section{Abbreviation}

3TC: Lamivudine; AIDS: Acquired ImmunoDefiency Syndrome; ARV: AntiRetroViral; ART: AntiRetroViral Treatment; DRC: Democratic Republic of Congo; EFV: Efavirenz; HIV: Human Immunodeficiency Virus; NVP: Nevirapine; PCR: Polymerase Chain Reaction; PGRHK: Provincial General Reference Hospital of Kinshasa; PLHIV: People Living with HIV; PMCT: Prevention of Mother-Child Transmission; PNC: PreNatal Consultation; TDF: Tenofovir. 